\title{
Retrospective longitudinal analysis of the effects of postnatal weight gain on the timing and tempo of puberty and menarche in a cohort of Italian girls
}

Vittorio Ferrari, Simona Stefanucci, Marta Ferrari, Daniele Ciofi, Stefano Stagi ${ }^{*}$ (i) and on the behalf of the Tuscany Menarche Study Group

\begin{abstract}
Objective: over the last few decades there has been a progressive decline in the average age of onset of pubertal development stages in both sexes. The increase in the prevalence of childhood obesity seems to play an important role in this phenomenon.
\end{abstract}

Design: we undertook a retrospective, longitudinal evaluation of the average age of thelarche and menarche to evaluate the relationship between $\mathrm{BMI}$ and weight change during the first years of life and the timing and tempo of puberty.

Methods: we evaluated data for 577 Italian girls born between 1995 and 2003. We collected the main auxological and clinical parameters, including age at B2 and at menarche, BMI SDS at B2 and menarche, gestational age and birth weight and Z-score change from birth weight (BW) to BMI at B2 and menarche.

Results: the mean age of B2 was 10.06 \pm 1.03 years and the mean age of menarche was $12.08 \pm 1.02$ years. Age at B2 and menarche were inversely correlated with BMI SDS $(p<0.0001)$. Both age at menarche and at thelarche have an inverse relationship with the Z-score change from birth weight and BMI at menarche and thelarche respectively $(p<0.0001)$.

Conclusions: our data confirm a significant relationship between BMI and age of B2 and menarche. We observed a clear relationship among weight change during the first years of life, age at thelarche and menarche and the duration of puberty, demonstrating the importance of weight and weight gain in determining the timing and tempo of pubertal changes and growth.

Keywords: Children, Postnatal weight gain, Age at thelarche, Age at menarche, Secular trend, Puberty, Onset of Puberty, Overweight, Public health, Epidemiology

${ }^{*}$ Correspondence: stefano.stagi@unifi.it

Department of Health Sciences, University of Florence, Anna Meyer

Children's University Hospital, viale Pieraccini 24, Florence, Italy

\section{Introduction}

The average age of pubertal development has decreased all over the world, particularly in females [1]. The reasons for this phenomenon include changes in nutritional status, an increase in the prevalence of childhood obesity and increasingly frequent exposure to endocrine-disruptors $[1,2]$. Some data carried out during the Sars-CoV2 original author(s) and the source, provide a link to the Creative Commons licence, and indicate if changes were made. The images or other third party material in this article are included in the article's Creative Commons licence, unless indicated otherwise in a credit line to the material. If material is not included in the article's Creative Commons licence and your intended use is not permitted by statutory regulation or exceeds the permitted use, you will need to obtain permission directly from the copyright holder. To view a copy of this licence, visit http://creativecommons.org/licenses/by/4.0/. The Creative Commons Public Domain Dedication waiver (http://creativeco mmons.org/publicdomain/zero/1.0/) applies to the data made available in this article, unless otherwise stated in a credit line to the data. 
pandemic underlined the importance of environmental factors in the timing and tempo of pubertal development, showing an increase of central precocious and fast puberty (CPP) in girls during and following the first lockdown in Italy from March to May 2020 [3, 4]. Among the factors hypothesized to be related to this phenomenon were nutritional factors related to an increased BMI, an "overuse" of electronic devices and psychological triggers [3].

In girls with a normal BMI, there is significant evidence, although mostly from cross-sectional studies [57], indicating that BMI influences the timing of thelarche $[2,5,6,8]$ and menarche [2, 7]. Increased adiposity appears to decrease the age of onset and accelerate the progression of puberty. Studies indicate that a larger gain in BMI during childhood whether in the first 20 months [8], in the first 5 years [9] or between the ages of two and eight years [10] is related to an earlier onset of puberty. There also appears to be a relationship between age of pubertal onset and weight at birth $[9,11]$.

Insulin resistance and excess hepato-visceral fat may play an important role in determining the appearance of the first signs of pubertal development. In these subjects, the early appearance of pubertal development could be a mechanism to minimise increases in central ectopic fat [12]. According to this theory, the Z-score change from birth weight (BW) to BMI in childhood would be a good marker of the metabolic conditions influencing the timing and tempo of puberty in normal girls [12].

In this study we evaluated the relationship between $\mathrm{Z}$-score change from $\mathrm{BW}$ to $\mathrm{BMI}$ at thelarche and menarche and the timing and tempo of puberty in a large cohort of Tuscany girls.

\section{Patients and methods}

We carried out a monocentric, retrospective, longitudinal and observational study. We collected the data of 577 girls born between 1995 and 2003 who had reached menarche by the time of the study. We extrapolated the data from the program 'Infantia 2000', commonly used by family paediatricians in Italy, selecting 22 paediatric clinics in Tuscany (central Region of Italy), on the basis of the auxological skills of the paediatricians and the frequency of follow-up visits.

The data collected from medical records was: weight, height, BMI (and respective standard deviation score (SDS)), age of onset of thelarche and menarche (selfreported by families at the time of the nearest visit), weight and height at birth (and respective SDS), maternal and paternal information, history of gestational diabetes, gestational and delivery information.

To calculate the standard deviation scores of the neonatal data (weight and length at birth) we considered the
Italian Neonatal Study [INeS] charts [13]; for the auxological parameters (height, weight and BMI at the time of thelarche and menarche) we used the Italian crosssectional growth charts of Cacciari et al [14]. Girls with a BMI below the $5^{\text {th }}$ centile were considered as underweight, those above the $85^{\text {th }}$ centile overweight, while all others were defined as normal weight [15].

The stages of pubertal maturation were assessed according to the Tanner and Whitehouse criteria [16]. The age of pubertal onset was defined as the age at durable Tanner B2 stage. The duration of puberty was considered as the period between the onset of thelarche and menarche. Final stature was the height reached by girls at least 2 years after menarche.

The exclusion criteria were: adoption; hormonal treatment for endocrinological disorders; therapies based on glucocorticoids, chemotherapy or GnRH analogues; history of chronic diseases such as celiac disease, anorexia, and history of tumours; girls who were SGA (defined as a weight and/or length less than 2 standard deviation [17]) were also excluded because more prone to earlier pubertal development and menarche, and faster progression of puberty than children born appropriate for gestational age (AGA) $[18,19]$. To evaluate the influence of the accumulation of central ectopic fat on the age of pubertal development we used the formula described by de Zegher et al [12, 20].

\section{Results}

The mean age of thelarche was $10.06 \pm 1.03$ years and the mean age of menarche was $12.08 \pm 1.02$ years. For girls with a normal BMI, the mean ages of B2 and menarche were $10.15 \pm 0.99$ years and $12.13 \pm 0.95$ years, respectively. For girls with a low BMI, B2 occurred on average at $10.62 \pm 1.02$ years and menarche at $13.20 \pm 1.15$ years $(p<0.0001)$, significantly later than girls with higher BMIs. Overweight girls reached B2 and menarche significantly earlier, on average at $9.47 \pm 0.93$ years and $11.27 \pm 0.83$ years $(p<0.0001)$ respectively (Table 1$)$. The age of thelarche and menarche was inversely related to the BMI SDS (respectively $R=0.34$ and $0.46 ; p<0.0001$ ).

The mean gestational age of our study group was $39.9 \pm 1.6$ weeks. We did not observe statistically significant differences in the age of thelarche and menarche in preterm $(<37$ weeks $)$ and full term girls. Nor did we observe a statistically significant correlation between age at thelarche and menarche and gestational age and length at birth.

We found a significant correlation (R: $0.27 ; p<0.0001)$ between age at thelarche and the Z-score change between BW and BMI at B2. (Fig. 1a) This correlation is slightly less pronounced than that present between age 
at thelarche and BMI Z-score at B2 (R: 0.34; $p<0.0001$ ) (Table 2).

We also found a statistically significant relationship between age at menarche and the Z-score change between BW and BMI (R: 0.38; $p<0.0001$ ). (Fig. 1b) This correlation is weaker than that between age at menarche and BMI Z-score at the time of the first menstrual cycle (R: $0.46 ; p<0.0001$ ) (Table 2).

We also evaluated the relationship between the duration (tempo) of puberty and the BMI Z-score change between thelarche and menarche. We observed a statistically significant relationship between these parameters definitive height and age of appearance of the breast budding. We did, however, observe a linear relationship (R: $0.13 ; p<0.05)$ between Z-score change in BMI between thelarche and menarche and definitive height Z-score. The direction of the trend line suggests that a greater variation in weight during puberty (and therefore a shorter duration) is associated with a lower final height of girls.

\section{Discussion}

Our data confirm a clear relationship between BMI and age at thelarche and menarche, as is reported in the literature $[2,5-8]$. They also suggest that the Z-score change

Table 1 Thelarche and menarche ages in relation to the BMl growth chart centiles ${ }^{a}$

\begin{tabular}{lllll}
\hline BMI (centiles) & Subjects (\%) & Thelarche age (yrs) & Subjects (\%) & Menarche age (yrs) \\
\hline Underweight & $32(5.5)$ & $10.62 \pm 1.02$ & $30(5.2)$ & $13.20 \pm 1.15$ \\
Normal weight & $457(79.2)$ & $10.15 \pm 0.99$ & $478(82.8)$ & $12.13 \pm 0.95$ \\
Overweight & $88(15.3)$ & $9.47 \pm 0.93$ & $69(12.0)$ & $11.27 \pm 0.83$ \\
\hline
\end{tabular}

${ }^{a}$ According the Italian cross-sectional growth charts of Cacciari et al. [14]; Underweight: BMI below the 5 th centile; normal weight: BMI between 5 and $85^{\text {th }}$ centile; overweight: BMI above the 85th centile[15]

(R: $0.13 ; p<0.05)$ (Fig. 2a). This result could be indicative of a further contribution of weight gain after entering puberty in determining the age of onset of menarche and in regulating the end of pubertal growth. We ascertained a statistically valid relationship between the tempo of puberty and the Z-score change between $\mathrm{BW}$ and $\mathrm{BMI}$ at B2 (R: $0.20 ; p<0.0001$ ) (Fig. 2b) (Table 2) suggesting that weight gain in the first years of life has a significant effect on the timing of puberty (11-13).

We evaluated the influence of BW on the age of onset of pubertal development. There was no statistical correlation between age at $\mathrm{B} 2$ and BW Z-score $(p>0.05)$.

Finally, we calculated the average final heights of the girls in our study: $161.51 \pm 6.23 \mathrm{~cm}$, in line with the average height of our previous study (2). We did not observe a statistically significant relationship between between BW and BMI is able to influence the timing of puberty and age at menarche, confirming the relationship between earlier pubertal maturation and increased BMI or adiposity in girls [2] and indicating the importance of the early weight gain from birth in the timing of the appearance of these phenomena.

Interestingly, the variation in BMI between age at thelarche and menarche and the Z-score change between $\mathrm{BW}$ and BMI at thelarche also has a relationship with the 'tempo' of puberty, suggesting that early weight gain between BW and BMI at thelarche also influences the duration of puberty. Among the numerous factors that could influence the timing and tempo of pubertal development are foetal nutrition, birth weight, childhood dietary habits, physical activity, psychological factors, exposure to electromagnetic fields (EMF) and/or

Table 2 Correlation values regarding BMI Z-score at age at thelarche and menarche, the $\triangle$ between birth weight Z-score and BMI Z-score at thelarche and menarche and the $\triangle$ of BMI Z-score between thelarche and menarche

\begin{tabular}{|c|c|c|c|}
\hline Weight changes parameters & Auxological parameters & Correlation coefficient (R) & $P$ value \\
\hline BMI Z-score at thelarche & Age at thelarche & 0.34 & $<0.0001$ \\
\hline BMI Z-score at menarche & Age at menarche & 0.46 & $<0.0001$ \\
\hline$\triangle B W$ vs. BMI Z-scores at thelarche ${ }^{a}$ & Age at thelarche & 0.27 & $<0.0001$ \\
\hline$\triangle B W$ vs. BMI Z-scores at menarche ${ }^{a}$ & Age at menarche & 0.38 & $<0.0001$ \\
\hline$\triangle B W$ vs. BMI Z-scores $\Delta$ at menarche ${ }^{a}$ & Tempo of puberty & 0.20 & $<0.0001$ \\
\hline$\triangle$ BMI vs. BMI Z-scores ${ }^{\mathrm{b}}$ & Tempo of puberty & 0.13 & $<0.05$ \\
\hline$\triangle B M I$ vs. BMI Z-scores ${ }^{\mathrm{a}}$ & Final height Z-score & 0.13 & $<0.05$ \\
\hline
\end{tabular}

$B W$ birth weight, $B M I$ body mass index

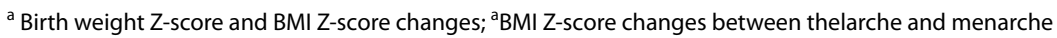



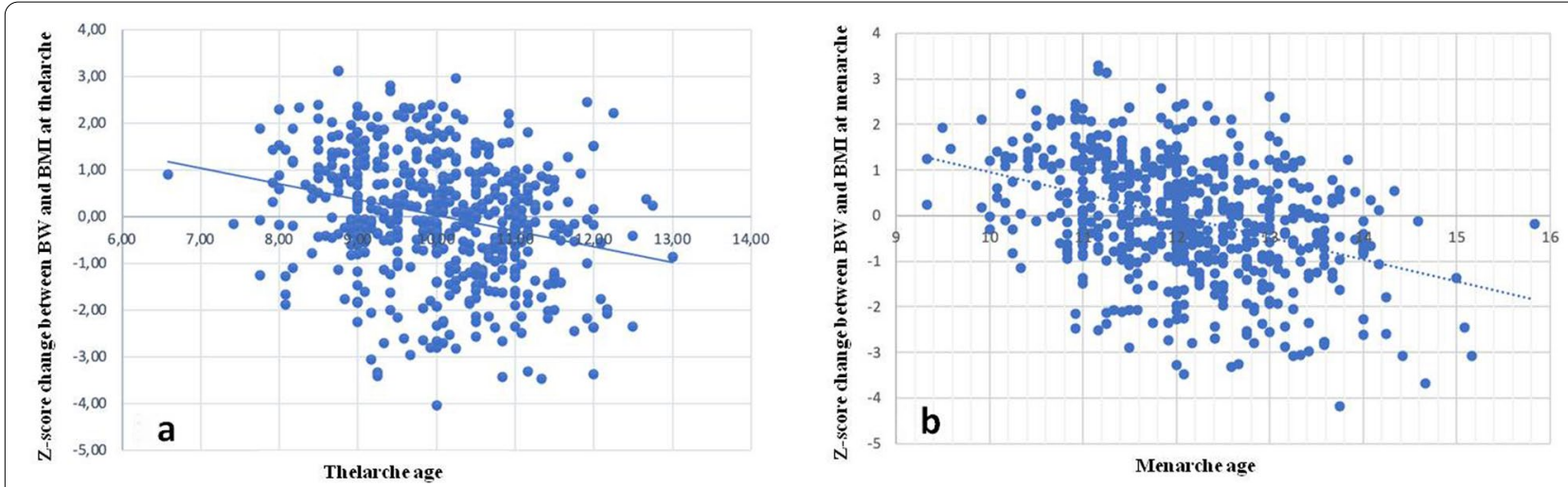

Fig. 1 Correlation between age at thelarche (B2) and the Z-score change between BW and BMI at B2. (R: 0.27; $p<0.0001 ; \mathbf{a})$ and between age at menarche and the Z-score change between the previously mentioned parameters $(\mathrm{R}: 0.38 ; p<0.0001 ; \mathbf{b})$
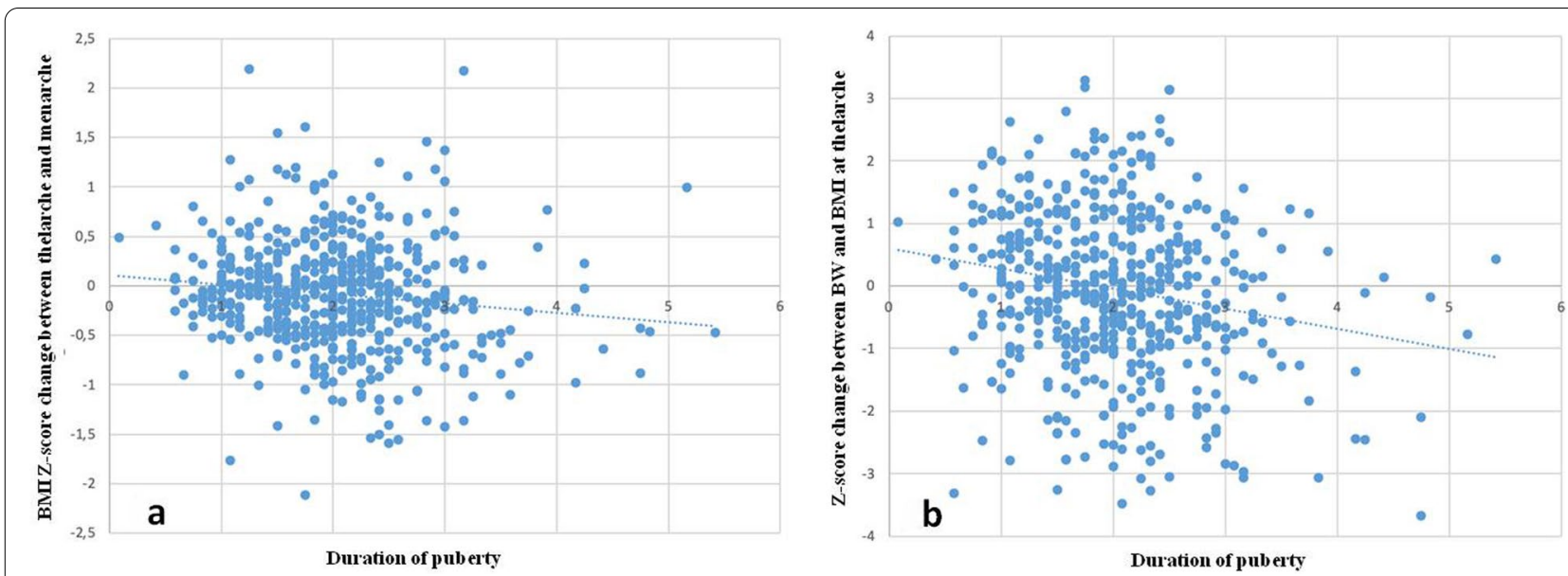

Fig. 2 Relationship between the tempo of puberty and the Z-score change between BW and BMI at menarche (R: 0.13; $p<0.05 ; \mathbf{a})$ and between the tempo of puberty and the Z-score change between BW and BMI at B2 (R: $0.20 ; p<0.0001 ; \mathbf{b})$

endocrine disrupting, the activating effect of leptin on $\mathrm{GnRH}-$ gonadotropin axis and hyperinsulinemia related to obesity [21].

Many data have demonstrated an association between adiposity and early puberty, particularly in girls; for example, a Pediatric Research in Office Settings (PROS) study showed that 6-9-year-old girls with breast development had higher BMI z-scores compared to prepubertal girls [6], and that the prevalence of excess weight is significantly higher in girls with early puberty than in controls [9]. The National Health Examination Survey (NHES 1963-1970) and National Health and Nutrition Examination Survey III (NHANES 1988-1994), examining trends in menarche age over 25 years, reported that age at menarche decreased from 12.7 to 12.5 years whereas the percentage of girls classed as overweight increased from 16 to $27 \%$ [22]. Early menarche is more prevalent in overweight girls than in normal weight girls [23], suggesting a causality between increasing obesity and lower age at menarche.

Unfortunately, many of these studies are cross-sectional. Longitudinal studies investigating the association between changes in body composition and pubertal timing and tempo in girls are very poor [24], because they relate to only one pubertal parameter [7] or use selfreported data [25].

Our data do not show a significant correlation between age at thelarche and adult height, supporting previous data in the literature [26], although there is a negative relationship between the change in BMI Z-score from thelarche to menarche and adult height. An increase in BMI during puberty is related to a reduced adult height, probably due to the reduced duration of puberty in these girls. 
Some data clearly show that higher BMI Z-scores in infancy and childhood are associated with faster length/height velocity in early life, while higher BMI z-scores during mid-childhood are associated with slower length/height velocity during adolescence [27]. This may be particularly important for girls with fast puberty, considering that puberty may follow a nonlinear trajectory with significant interindividual differences of timing and tempo [2, 28]. Further studies will be necessary to better evaluate this finding.

Our study is limited by the fact that we did not have data on weight change for patients with precocious puberty. Future studies would ideally include reliable measurements of body fat mass as well as BMI, hormonal markers for pubertal development and be longitudinal to overcome genetic, nutritional and environmental variables.

In conclusion, our data confirm a significant relationship between BMI and age at B2 and menarche in Italian girls, as well as a clear relationship among weight changes during the first years of life, age at thelarche and menarche and the duration of puberty. There is increasing evidence that environmental factors explain consistent and continuous variations in the onset and tempo of puberty.

\section{Acknowledgements}

Thanks to Tammy Ann Corkish BA MA for advice on the use of clear English.

\begin{abstract}
Authors' contributions
Vittorio Ferrari carried out the endocrinological evaluations, data interpretation and participated in the design of the study.Email: vittorioferrari15@ gmail.com. Simona Stefanucci carried out the endocrinological evaluations, data interpretation and participated in the design of the study. Email: simona. stefanucci@gmail.com. Marta Ferrari carried out the endocrinological evaluations, data interpretation and participated in the design of the study. Email: marta.ferrari@unifi.it. Daniele Ciofi carried out the data interpretation and participated in the design of the study. Email: daniele.ciofi@meyer.it. Stefano Stagi carried out endocrinological evaluations, conceived the study and participated in its design and coordination. stefano.stagi@unifi.t. All authors read and approved the final manuscript.
\end{abstract}

\section{Funding}

No external funding was provided for this study.

\section{Availability of data and materials}

Yes

\section{Declarations}

\section{Ethics approval and consent to participate}

The study was performed according to the Helsinki II declaration and approved by the local Paediatric Ethical Committee (Paediatric Ethical Committee - Tuscany Region, approval number: 65/2019, in date 03/09/2019).

\section{Consent for publication}

Written informed consent was obtained from the parents of enrolled children.

\section{Competing interests}

The authors have no conflicts of interest to declare.
Received: 29 August 2021 Accepted: 22 January 2022

Published online: 03 February 2022

\section{References}

1. Farello G, Altieri C, Cutini M, Pozzobon G, Verrotti A. Review of the literature on current changes in the timing of pubertal development and the incomplete forms of early puberty. Front Pediatr. 2019;7:147-53. https:// doi.org/10.3389/fped.2019.00147.

2. Ferrari V, Stefanucci S, Ciofi D, Stagi S. Analysis of the timing of puberty in a recent cohort of Italian girls: evidence for earlier onset compared to previous studies. J Pediatr Adolesc Gynecol. 2021;S1083-3188(21):00223. https://doi.org/10.1016/j.jpag.2021.06.007.

3. Stagi S, De Masi S, Bencini E, Losi S, Paci S, Parpagnoli M, et al. Increased incidence of precocious and accelerated puberty in females during and after the Italian lockdown for the coronavirus 2019 (COVID-19) pandemic. Ital J Pediatr. 2020;46(1):165-74. https://doi.org/10.1186/ s13052-020-00931-3.

4. Verzani M, Bizzarri C, Chioma L, Bottaro G, Pedicelli S, Cappa M. Impact of COVID-19 pandemic lockdown on early onset of puberty: experience of an Italian tertiary center. Ital J Pediatr. 2021;47(1):52-4. https://doi.org/10. 1186/s13052-021-01015-6.

5. Ma HM, Du ML, Luo XP, Chen SK, Liu L, Chen RM, et al. Pubertal study group of the society of pediatric endocrinology and genetic disease, Chinese medical association. Onset of breast and pubic hair development and menses in urban chinese girls. Pediatrics. 2009;124(2):e269-277. https://doi.org/10.1542/peds.2008-2638.

6. Kaplowitz PB, Slora EJ, Wasserman RC, Pedlow SE, Herman-Giddens ME. Earlier onset of puberty in girls: relation to increased body mass index and race. Pediatrics. 2001;108:347-53. https://doi.org/10.1542/peds.108.2. 347.

7. Freedman DS, Khan LK, Serdula MK, Dietz WH, Srinivasan SR, Berenson GS. Relation of age at menarche to race, time period, and anthropometric dimensions: the bogalusa heart study. Pediatrics. 2002;1 10: e43. https:// doi.org/10.1542/peds.110.4.e43.

8. Maisonet M, Christensen KY, Rubin C, Holmes A, Flanders WD, Heron J, et al. Role of prenatal characteristics and early growth on pubertal attainment of British girls. Pediatrics. 2010;126(3):e591-600. https://doi.org/10. 1542/peds.2009-2636.

9. Wang Y, Dinse GE, Rogan WJ. Birth weight early weight gain and pubertal maturation: a longitudinal study. Pediatr Obes. 2012;7(2):101-9. https:// doi.org/10.1111/j.2047-6310.2011.00022.x.

10. He Q, Karlberg J. Bmi in childhood and its association with height gain, timing of puberty, and final height. Pediatr Res. 2001;49:244-51. https:// doi.org/10.1203/00006450-200102000-00019.

11. Karaolis-Danckert N, Buyken AE, Sonntag A, Kroke A. Birth and early life influences on the timing of puberty onset: results from the DONALD (DOrtmund Nutritional and Anthropometric Longitudinally Designed) study. Am J Clin Nutr. 2009;90:1559-65. https://doi.org/10.3945/ajcn. 2009.28259.

12. de Zegher F, Ibanez L. On the rising incidence of early breast development: puberty as an adaptive escape from ectopic adiposity in mismatch girls. Eur J Endocrinol. 2021;185(1):L1-2. https://doi.org/10.1530/ EJE-21-0287.

13. Bertino E, Di Nicola P, Varalda A, Occhi L, Giuliani F, Coscia A. Neonatal growth charts. J Matern Fetal Neonatal Med. 2012;25(Suppl 1):67-9. https://doi.org/10.3109/14767058.2012.664889.

14. Cacciari E, Milani S, Balsamo A, Spada E, Bona G, Cavallo L, et al. Italian cross-sectional growth charts for height, weight and BMI (2 to $20 \mathrm{yr}$ ). J Endocrinol Invest. 2006;29(7):581-93. https://doi.org/10.1007/BF033 44156.

15. Weir CB, Classification Jan A. BMI, Points Percentile And Cut Off. StatPearls Treasure Island (FL): StatPearls Publishing; 2021. (2021 Jan-).

16. Tanner JM, Whitehouse RH. Clinical longitudinal standards for height, weight, height velocity, weight velocity and stages of puberty. Arch Dis Child. 1976;51 (3):170-9. https://doi.org/10.1136/adc.51.3.170.

17. Clayton PE, Cianfarani S, Czernichow P, Johannsson G, Rapaport R, Rogol A. Management of the child born small for gestational age through to adulthood: a consensus statement of the international societies of pediatric endocrinology and the growth hormone research society. J 
Clin Endocrinol Metab. 2007;92(3):804-10. https://doi.org/10.1210/jc. 2006-2017.

18. Renes JS, Willemsen RH, Mulder JC, Bakker-van Waarde WM, Rotteveel J, Oostdijk W, et al. New insights into factors influencing adult height in short SGA children: results of a large multicentre growth hormone trial. Clin Endocrinol (Oxf). 2015;82(6):854-61. https://doi.org/10.1111/cen. 12677.

19. Verkauskiene R, Petraitiene I, Albertsson WK. Puberty in children born small for gestational age. Horm Res Paediatr. 2013;80(2):69-77. https:// doi.org/10.1159/000353759.

20. de Zegher F, Malpique R, Garcia-Beltran C, Ibanez L. Towards a simple marker of hepato-visceral adiposity and insulin resistance: the Z-score change from weight-at-birth to BMI-in-childhood. Pediatr Obes. 2019;14(10): e12533. https://doi.org/10.1111/ijpo.12533.

21. Li W, Liu Q, Deng X, Chen Y, Liu S, Story M. Association between obesity and puberty timing: a systematic review and meta-analysis. Int J Environ Res Public Health. 2017;14(10):1266. https://doi.org/10.3390/ijerph1410 1266.

22. Anderson SE, Dallal GE, Must A. Relative weight and race influence average age at menarche: results from two nationally representative surveys of US girls studied 25 years apart. Pediatrics. 2003;111(4 Pt 1):844-50. https://doi.org/10.1542/peds.111.4.844.

23. Rosenfield RL, Lipton RB, Drum ML. Thelarche, pubarche, and menarche attainment in children with normal and elevated body mass index. Pediatrics. 2009;123:84-8. https://doi.org/10.1542/peds.2008-0146.

24. Buyken AE, Karaolis-Danckert N, Remer T. Association of prepubertal body composition in healthy girls and boys with the timing of early and late pubertal markers. Am J Clin Nutr. 2009;89(1):221-30. https://doi.org/ 10.3945/ajcn.2008.26733.

25. Mamun AA, Hayatbakhsh MR, O'Callaghan M, Williams G, Najman J. Early overweight and pubertal maturation-pathways of association with young adults' overweight: a longitudinal study. Int J Obes (Lond). 2009:33(1):14-20. https://doi.org/10.1038/ijo.2008.220.

26. Herman-Giddens ME, Slora EJ, Wasserman RC, Bourdony CJ, Bhapkar MV, Koch GG, Hasemeier CM. Secondary sexual characteristics and menses in young girls seen in office practice: a study from the pediatric research in office settings network. Pediatrics. 1997;99(4):505-12. https://doi.org/10. 1542/peds.99.4.505.

27. Aris IM, Rifas-Shiman SL, Zhang X, Yang S, Switkowski K, Fleisch AF, et al. Association of BMI with linear growth and pubertal development. Obesity (Silver Spring). 2019;27(10):1661-70. https://doi.org/10.1002/oby. 22592.

28. Tanner JM. Sequence, tempo, and individual variation in the growth and development of boys and girls aged twelve to sixteen. Daedalus. 1971;100:907.

\section{Publisher's Note}

Springer Nature remains neutral with regard to jurisdictional claims in published maps and institutional affiliations.

Ready to submit your research? Choose BMC and benefit from:

- fast, convenient online submission

- thorough peer review by experienced researchers in your field

- rapid publication on acceptance

- support for research data, including large and complex data types

- gold Open Access which fosters wider collaboration and increased citations

- maximum visibility for your research: over $100 \mathrm{M}$ website views per year

At BMC, research is always in progress.

Learn more biomedcentral.com/submissions 